\title{
Artificial neural network for predicting the flexural bond strength of FRP bars in concrete
}

https://doi.org/10.1515/secm-2017-0155

Received May 28, 2015; accepted April 24, 2018; previously published online August 31, 2018

\begin{abstract}
The bond strength between fibre-reinforced polymer (FRP) rebars and concrete is one of the most significant aspects of composite behaviour for rebars and concrete. In this study, a database of 408 beam type specimens consisting of beam end specimens, beam anchorage specimens and splice beam specimens was compiled from the current literature and used to develop a simple prediction using the artificial neural network (ANN). The data used for modelling were organised in a format of eight input parameters that include FRP type, cover bar surface, confinement, bar diameter $\left(d_{b}\right)$, concrete compressive strength $\left(\sqrt{f_{c}}\right)$, minimum cover-to-bar-diameter ratio $\left(c / d_{b}\right)$, bar-development-length-to-bar-diameter ratio $\left(l / d_{b}\right)$, and the ratio of the area of transverse reinforcement to the product of transverse reinforcement spacing, the number of developed bars and bar diameters $\left(A_{t} / s n d_{b}\right)$. Additionally, a simple prediction formula by regression analysis was developed. The root mean square error and $R^{2}$ values of the testing data were found in order to compare the results of both ANN and the proposed model with existing regulations. The new ANN model predicts the bond strength of FRP bars in reinforced concrete with $0.8989 R^{2}$, thus yielding better results when compared with existing regulations.
\end{abstract}

Keywords: ANN; bond strength; FRP bars.

\section{Introduction}

Fibre-reinforced polymer (FRP), which extends the service life of reinforced concrete structures, has been popular in structural construction for the last two decades. The use of non-corrosive FRP reinforcement presents some positive properties, such as low weight, high tensile strength, noncorrosiveness and resistance to magnetic and electrical fields. However, the indefinite yield plateau of the stressstrain curve plus the low elastic modulus of some FRPs

\footnotetext{
*Corresponding author: Mehmet Alpaslan Köroğlu, Civil Engineering Department, Necmettin Erbakan University, 42090 Konya, Turkey, e-mail: makoroglu@konya.edu.tr
}

O Open Access. (c) BY (C) 2019 Walter de Gruyter GmbH, Berlin/Boston compared to steel reinforcements can affect the composite action between FRP and concrete. The contact interface between the concrete and the surface of the bar develops a magnitude of bond that affects this composite action [1].

Several studies have been conducted in order to investigate the bond performance of FRP bars and to compare such bond properties with steel reinforcement in concrete. These studies include tests on beams and pull-out specimens [2-4]. Both of these tests, which were carried out to measure the bond strength of reinforcing bars, give different values. Experimental studies have shown that the bond strength from beam tests is lower than that from pull-out tests [4]. The absence of local bending on the bar, a thick concrete cover and the confining effect of the reaction plate on the concrete specimen mean that the concrete does not split, thus improving the bond strength of the concrete under compression in the pull-out tests. Conversely, the concrete around the reinforcing rebars that run the length of the span is prone to cracking under low stresses and a decrease in the bond strength when under tension. Therefore, the pull-out test results for bond strength, taking into account the upper-bound value for the bond stress-slip performance of FRP bars, can be unrealistic as opposed to beam tests that simulate the real flexural behaviour of concrete members [5].

Previous beam tests investigating bond behaviour between FRP bars and concrete have focussed mainly on the different parameters affecting bond strength, such as the compressive strength of concrete, concrete cover, bar diameter, embedment length, bar cast position, type of fibres, type of rebar surface and transverse reinforcement.

Artificial neural network (ANN) and genetic programming (GP), various branches of soft computing, have been used popularly in many studies for different structural engineering applications in the last two decades [6-11]. Data for pull-out tests that had been carried out on ribbed steel rebars to investigate bond strength were collected from the literature, and an ANN-based model was used to predict the ultimate bond strength in a study by Dahou et al. [12]. An ANN and fuzzy logic (FL) model was developed by Golafshani et al. in 2012 in order to predict the bond strength of steel bars in concrete using 179 records taken from the literature [13]. They obtained acceptable prediction results with both the ANN and FL models, while for this study the ANN predicted ultimate bond strength 
more accurately than did FL [13]. Golafshani et al. in 2015 also studied 159 experimental data including notched, hinged, spliced, and inverted hinge beam specimens to predict the ultimate bond strength of glass FRP (GFRP) bars in concrete using both ANN and GP. The developed ANN and GP models predicted the bond strength of GFRP bars much better than the multi-linear regression model and present code equations [14].

In this study, a very extensive database of beam type specimen consisting of beam end specimens, beam anchorage specimens and splice beam specimens was created from the current literature in order to predict the bond strength of FRP bars in concrete using ANN. To this end, a database consisting of 408 experimental records for beam type specimens taken from the literature was used. The data used in these models were set in a format of eight input parameters: FRP type, cover bar surface, confinement, bar diameter $\left(d_{b}\right)$, concrete compressive strength $\left(\sqrt{f_{c}}\right)$, minimum cover-to-bar-diameter ratio $\left(c / d_{b}\right)$, bardevelopment-length-to-bar-diameter ratio $\left(l / d_{b}\right)$ and the ratio of the area of transverse reinforcement to the product of the transverse reinforcement spacing, the number of developed bars and bar diameters and an output parameter that is the bond strength $\left(\tau_{s}\right)$. Additionally, a simple prediction formula was developed for the same data using regression analysis. The results obtained from both the proposed ANN model and the regression analysis model were compared with experimental results and existing building code equations.

\section{Flexural bond}

If two neighbouring sections along the bar at a distance $d x$ and located in part 1 for the bar are taken, the flexural stresses in a part $d x$ are shown as in Figure 1. Supposing a uniformly distributed bond stress, the following equation is applied:

$$
\mu \pi \varnothing d x=d T,
$$

then

$$
\mu=\frac{1}{\pi \varnothing} \frac{d T}{d x}
$$

or

$$
\mu=\frac{1}{\pi \varnothing} \frac{V}{y_{c t}},
$$

where $\mu$ is the bond stress, $d T$ is the force changing in the reinforcing bars with an interval $d x, \varnothing$ is the diameter of the reinforcing bar, $V$ is the shear force and $y_{c t}$ is the distance between the resultant tensile stresses and the resultant compressive stresses.

Hereby, the bond strength is calculated by

$$
\begin{aligned}
& \mu(\pi \varnothing l)=A_{b} f_{b}, \\
& \mu=\frac{A_{b} f_{b}}{\pi \varnothing l}=\frac{\varnothing f_{b}}{4 l},
\end{aligned}
$$

where $l$ is embedment length, $f_{b}$ is the stress on the bar and $A_{b}$ is the nominal cross-section of the bar.

Pull-out tests and beam tests are used to determine bond strength and bond strength distribution. All sorts of experimental systems have been developed for determining the various bond characteristics of reinforcing bars in concrete [4]. A hinged beam test, which is used in Europe for estimating bond strength in accordance with the International Union of Laboratories and Experts in Construction Materials, Systems and Structures specification [15], is given in Figure 2A. The advantage of this test system is

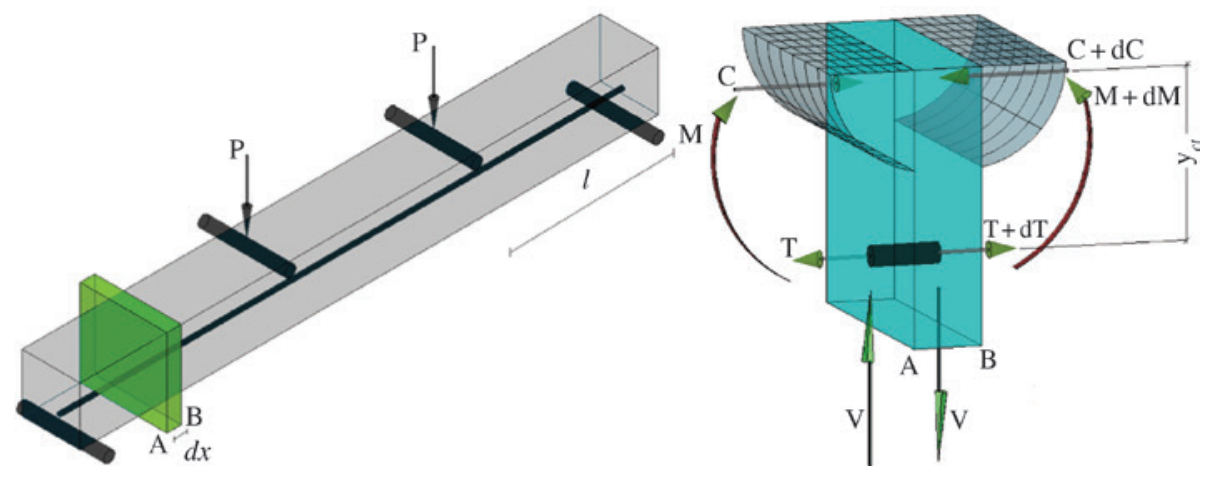

Figure 1: Flexural stresses in a part $d x$. 

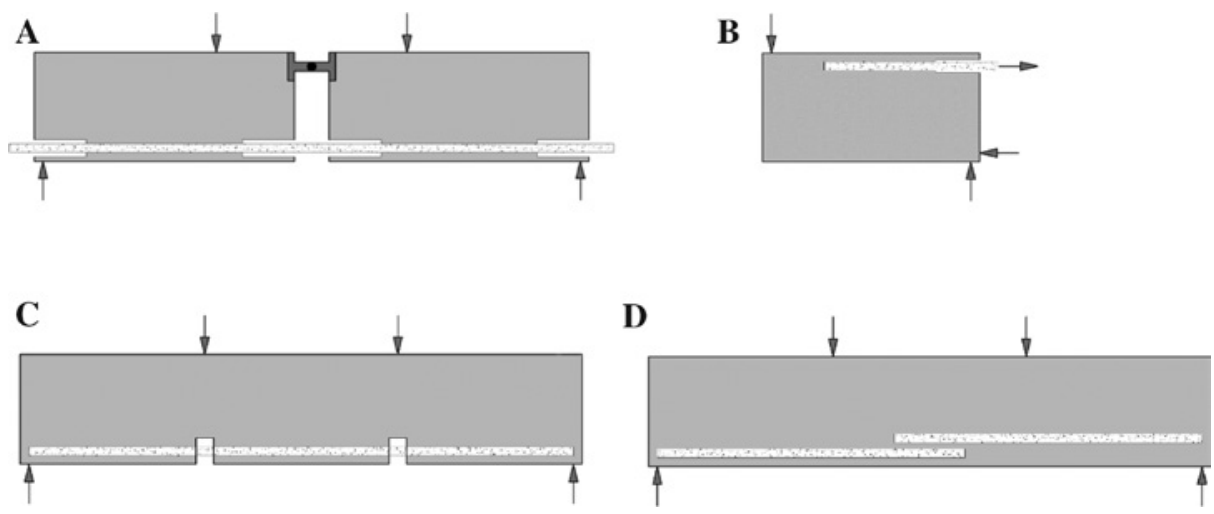

Figure 2: Beam tests for bonding. (A) Hinged beam test. (B) Beam end specimen (inverted hinge beam). (C) Beam anchorage specimen. (D) Beam splice specimen.

that the load is applied to the displacement of the rebar during bending, as opposed to pull-out tests in which the external load is applied directly to the rebar.

Beam end specimen is a modified form of cantilever beam (Figure 2B) that provides a comparatively simple test that usually duplicates the stress state attained in reinforced concrete members. While the reinforcing bar and surrounding concrete are positioned in tension, the compressive force is positioned away from the reinforcing bar with a balanced distance relative to the embedment length or the bonded length of the rebar in concrete. A short length of bar near the surface is covered to enhance the bonding between bar and concrete in order to inhibit a conical failure surface. The bonding test results from the cantilever beam tests closely match the results obtained from full-scale reinforced concrete beams. The beam anchorage and splice specimens given in Figure $2 \mathrm{C}$ and $\mathrm{D}$ are small-scale examples of full-scale specimens, and are produced specifically to evaluate splicing, bonding and development strength in larger full-scale beams. The beam anchorage specimen, also called the notched beam specimen, is cast with notches in the bottom representing a member with a flexural crack and measured bonded length. The beam is loaded directly over the notches on the top of the beam, as shown in Figure 2C. It is simpler to produce a splicing specimen (Figure 2D), which is simply supported with two applied point loads spliced in a constant bending moment zone, as opposed to the notched beam test, and gives approximately equal bond strengths. [4].

Tighiouart et al. [16] suggested the ultimate-equilibrium theory as given in Figure 3. According to the theory, FRP rebar force $T$ is calculated as

$$
T j=P a,
$$

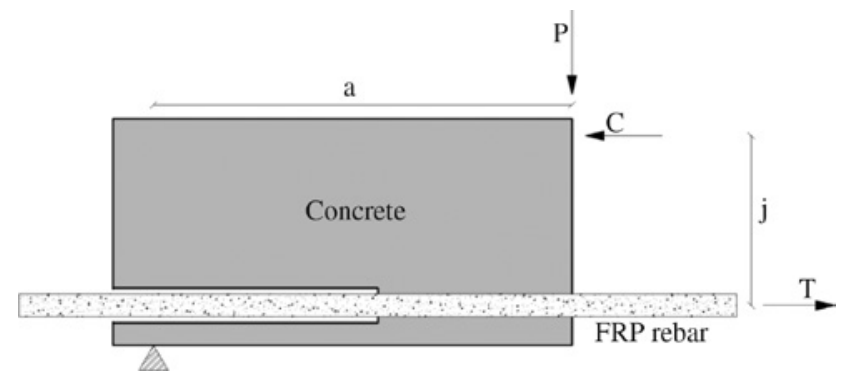

Figure 3: Theory of ultimate equilibrium on beam specimens.

$$
T_{\max }=\frac{P a}{j}
$$

and

$$
\tau_{\max }=\frac{T_{\max }}{P d l},
$$

where $T_{\max }$ is the ultimate load on the rebar, $d$ is the nominal diameter of the rebar, $l$ is the bond length and $\tau_{\max }$ is the maximum bond strength.

In hinged beam tests and beam end specimens, similar bond strength formation can clearly be seen using the ultimate-equilibrium theory. Additionally, Shihata [17] reported that spliced beam specimens produce bond strength results similar to beam anchorage specimens.

The flexural bond stress provided by the measured strain for beam tests where the neutral axis is mutable under increased loading is calculated as

$$
T=\epsilon E A,
$$

$$
\tau_{\text {max }}=\frac{\epsilon E A}{\pi d l},
$$


where $\epsilon$ is the measured strain of the FRP rebar, $E$ is the modulus of elasticity of the FRP rebar, $A$ is the cross-section of the FRP rebar, $d$ is the nominal diameter of the FRP rebar and $l$ is the bond length.

In addition to this, in the literature, Golafshani et al. [14] studied 159 experimental data including notched, hinged, spliced and inverted hinge beam specimens, and Yan and Lin [18] collected 179 beam test specimens to predict ultimate bond strength in GFRP bars in concrete using ANN. Therefore, in this study, it was decided to group all the beam tests together in order to estimate the bond strength of FRP rebars.

The bond mechanisms for FRP rebars and steel bars in concrete are different due to the force transfer and failure mechanism of rebars. The FRP bar surface is known as non-homogenous because the surface texture is produced by epoxy, several fibre orientations or sand coating. Benmokrane and Tighiouart [19] and Tighiouart et al. [5] reported that adhesion and friction are the essential parameters for the actual force transfer mechanisms between FRP rebar and concrete. It has been observed that the bond performance of FRP rebars is reduced because of their non-uniform composition. Wambeke and Shield [20] and Mosley et al. [21] confirmed that the surface texture of FRP rebars has no significant influence on bond strength. However, it was reported by Baena et al. [22] that the surface of the rebar affects the bond strength significantly on pull-out tests if the concrete matrix fails. In the light of this, it can be deduced that the influence of rebar surface on bond strength has not been identified definitively yet. In addition, a few researchers [3, 16, 23-25] have drawn attention to the spacing and height of the ribs on rebars in the literature.

\section{Data preparation}

Bond tests are classified into two main groups: pull-out tests and beam tests. As pull-out tests do not represent the real behaviour of reinforced concrete members, this study considers beam tests that represent a more realistic behaviour. A database of 408 beam type specimens consisting of hinged beams, beam end specimens, beam anchorage specimens and spliced beam specimens is created from the current literature [4, 14, 16, 19-21, 23, 26-51]. The maximum, minimum, mean and standard deviation values of input and output variables are given in Table 1.

Numbers 1, 2 and 3 for rebar type indicate carbon FRP (CFRP), GFRP and aramid FRP (AFRP), respectively. Also, numbers 1, 2, 3 and 4 for the rebar surface indicate
Table 1: Ranges of input and output parameters in the database.

\begin{tabular}{|c|c|c|c|c|c|}
\hline \multicolumn{2}{|l|}{ Parameters } & Minimum & Maximum & Mean & SD \\
\hline \multicolumn{2}{|l|}{ Type } & 1.00 & 3.00 & 1.83 & 0.45 \\
\hline \multicolumn{2}{|l|}{ Surface } & 1.00 & 3.00 & 2.00 & 0.88 \\
\hline \multicolumn{2}{|l|}{ Confining } & 1.00 & 2.00 & 1.59 & 0.49 \\
\hline \multicolumn{2}{|l|}{$d_{b}(\mathrm{~mm})$} & 6.38 & 28.58 & 15.59 & 5.10 \\
\hline \multicolumn{2}{|l|}{$v f_{c}(\mathrm{MPa})$} & 4.29 & 8.08 & 5.87 & 0.77 \\
\hline \multicolumn{2}{|l|}{$c / d_{b}$} & 0.92 & 9.34 & 2.97 & 1.39 \\
\hline \multicolumn{2}{|l|}{$l / d_{b}$} & 2.50 & 115.79 & 26.33 & 21.96 \\
\hline \multicolumn{2}{|l|}{$A_{t r} / s^{0} d_{b}$} & 0.00 & 0.15 & 0.02 & 0.03 \\
\hline \multicolumn{2}{|l|}{$\tau_{s}$} & 0.76 & 25.48 & 7.65 & 5.43 \\
\hline \multirow[t]{4}{*}{$20<f c<30(\mathrm{MPa})$} & $c / d_{b}$ & 1.00 & 5.67 & 2.97 & 1.48 \\
\hline & $l / d_{b}$ & 3.56 & 60.00 & 17.13 & 15.12 \\
\hline & $A_{t r} / s n d_{b}$ & 0.00 & 0.31 & 0.04 & 0.09 \\
\hline & $\tau_{s}$ & 0.78 & 25.48 & 10.46 & 7.16 \\
\hline \multirow[t]{4}{*}{$30<f c<40(\mathrm{MPa})$} & $c / d_{b}$ & 1.31 & 9.34 & 2.98 & 1.58 \\
\hline & $l / d_{b}$ & 5.00 & 115.79 & 30.58 & 25.23 \\
\hline & $A_{t r} /$ snd $_{b}$ & 0.00 & 0.39 & 0.06 & 0.10 \\
\hline & $\tau_{s}$ & 0.80 & 16.49 & 6.33 & 3.72 \\
\hline \multirow[t]{4}{*}{$40<f c<50(\mathrm{MPa})$} & $c / d_{b}$ & 1.25 & 6.00 & 2.61 & 0.75 \\
\hline & $l / d_{b}$ & 10.00 & 115.79 & 29.05 & 20.23 \\
\hline & $A_{t r} / s n d_{b}$ & 0.00 & 0.15 & 0.01 & 0.02 \\
\hline & $\tau_{s}$ & 0.76 & 15.89 & 5.21 & 2.08 \\
\hline \multirow[t]{4}{*}{$f c>50(\mathrm{MPa})$} & $c / d_{b}$ & 1.25 & 8.00 & 3.18 & 2.17 \\
\hline & $l / d_{b}$ & 10.67 & 50.78 & 29.94 & 16.85 \\
\hline & $A_{t r} / s n d_{b}$ & 0.00 & 0.08 & 0.01 & 0.03 \\
\hline & $\tau_{s}$ & 1.69 & 14.05 & 5.49 & 3.29 \\
\hline
\end{tabular}

helical lugged surfaces, sand-coated, spiral-wrapped, and spiral-wrapped sand-coated surfaces, respectively. Number 1 is used for confined beams, while number 2 is used for unconfined beams.

The researched database is divided by failure type mode: splitting failure and pull-out failure. In order to analyse the data, the bond stress is normalised in order to minimize the variability of the bond stress data relating to the compressive strength of the concrete. Furthermore, the embedment length and concrete cover are normalised by bar diameter in order to decrease the variability relating to bar diameter. The effect of the various parameters on the bond stress of FRP rebars in concrete is discussed in the subsequent sections.

Data analysis is conducted for various types of FRP rebars to find out the effect of fibre type on the bond behaviour of FRP rebars to concrete. The number of specimens with GFRP rebars is much higher than the number of specimens with both GFRP and AFRP rebars. The ratio for the normalised average bond stress $\left(\frac{\tau_{m}}{\sqrt{f_{c}}}\right)$ of the specimens to the normalised embedment length $\left(\frac{l_{\text {embed }}}{d_{b}}\right)$ of the specimens is plotted in Figure 4. In parallel to 


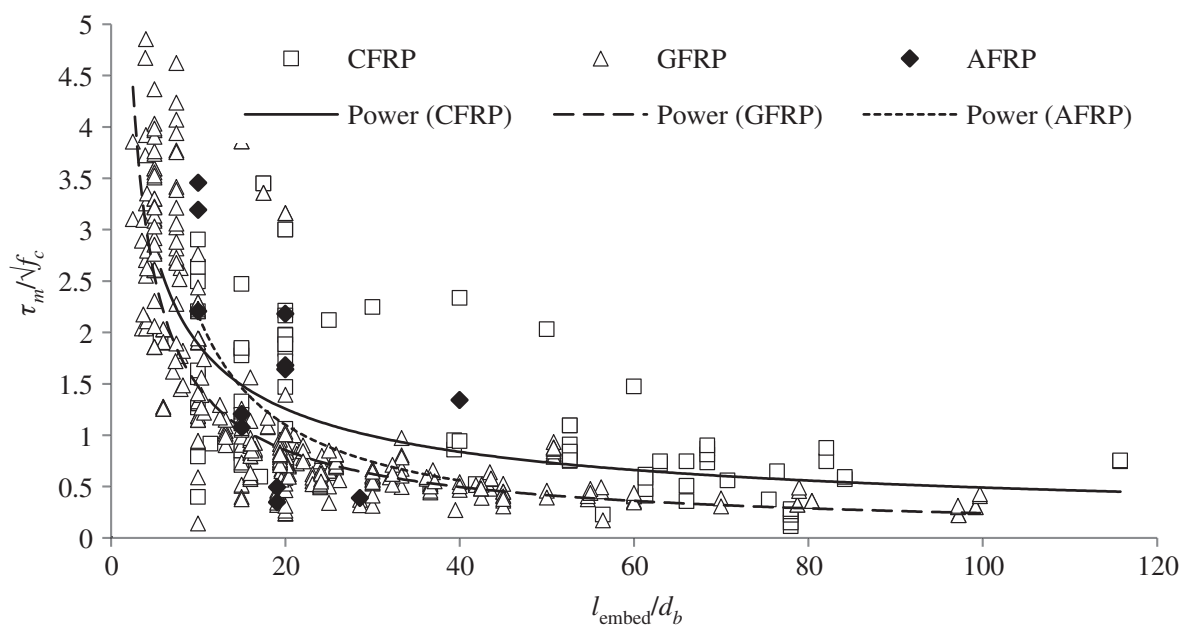

Figure 4: Normalised average bond stress $\left(\frac{\tau_{m}}{\sqrt{f_{c}}}\right)$ of specimens to normalised embedment length $\left(\frac{l_{\text {embed }}}{d_{b}}\right)$ ratio for different FRP types.

Canadian Standards Association (CSA) S806-02 [52], which suggests using a similar modification factor to calculate the required development length of FRP rebars in concrete for CFRP and GFRP, it was noted that the type of fibre has no significant effect on the bond strength of FRP rebars to concrete.

To analyse the effect of rebar surface type on the bond strength of FRP rebars to concrete, three different types of bar surface, helical lugged/ribbed, spiral wrapped and sand coated, are observed. The following observations are made from Figure 5 by plotting the normalised average bond stress of specimens against the normalised embedment length.

From Figure 5, it is seen that bars with sand coating have the highest bond strength compared to helical lugged/ribbed and spiral wrapped rebars. However, the type of rebar surface has no significant effect on the bond strength of FRP rebars to concrete.

It was seen in the literature that the average bond strength of FRP bars to concrete is reported as a function of the square root of concrete compressive strength. Therefore, in this study, the bond strength is plotted against the square root of concrete compressive strength for both splitting and pull-out bonding failures alike.

It is observed that bond strength is increased when the square root of concrete compressive strength is increased for both normal-strength and high-strength concrete (Figure 6).

The normalised average bond strengths for different concrete-cover-to-bar-diameter ratios for both splitting

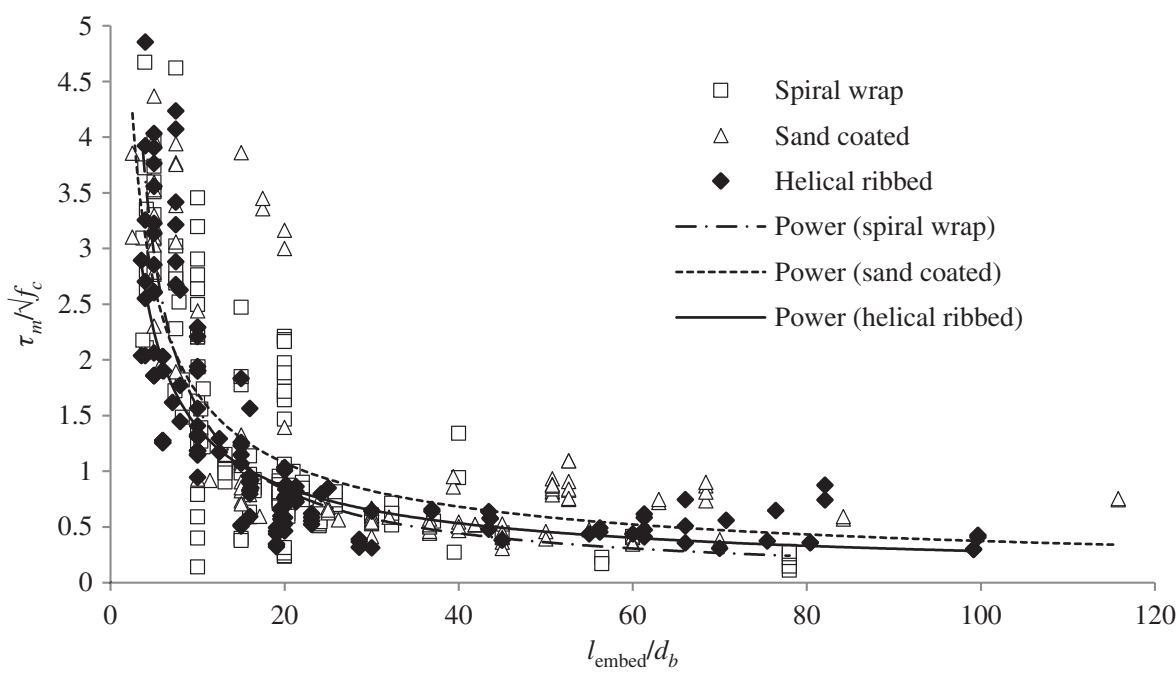

Figure 5: Normalised average bond stress of specimens against to the normalised embedment length for different bar surfaces. 


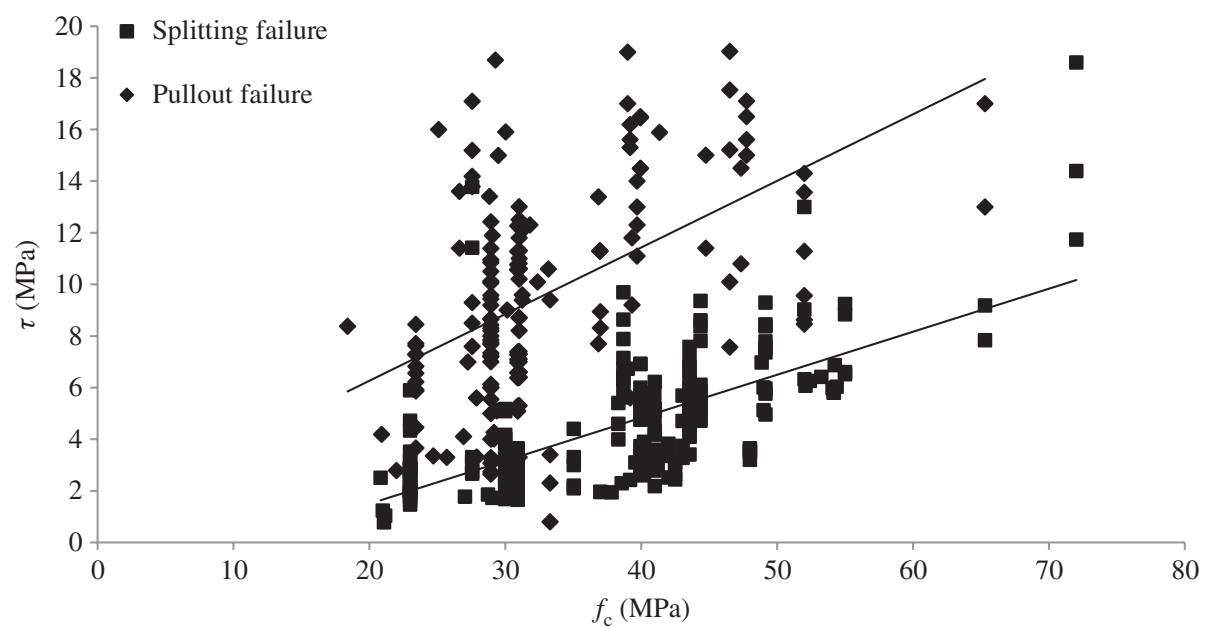

Figure 6: Bond stress of specimens against concrete strength.

and pull-out failure modes are given in Figure 7. It is clearly seen from the figures that when concrete cover increases, the bonding strength also increases. It is also observed that the bond strength of FRP bars for pull-out failure modes is higher than the bond strength of FRP bars for splitting failure modes.

In Figure 8, the variation of normalised average bond stress with normalised embedment length for both splitting and pull-out failures for bottom bar specimens is given. It is observed from Figure 8 that bond strength is reduced with an increase in embedment length for both failure types. The tensile strength of the rebar and bond strength both reduce as the embedment length increases due to the non-linear distribution of the bond strength.
Therefore, shorter development length results in higher bond strength [53].

The confinement effect on the bond strength of FRP rebars for both pull-out and splitting failure modes is shown in Figure 9. It is observed from Figure 9 that with respect to splitting failures, unconfined specimens having shorter normalised embedment lengths tend to have higher bond strengths for both failure types, while confined specimens have higher bond strengths than unconfined specimens for other embedment lengths. The presence of transverse reinforcement confining the concrete is accepted in the literature as a factor that limits the development of cracks while increasing the bond strength. Nevertheless, the theory has not been definitively proven

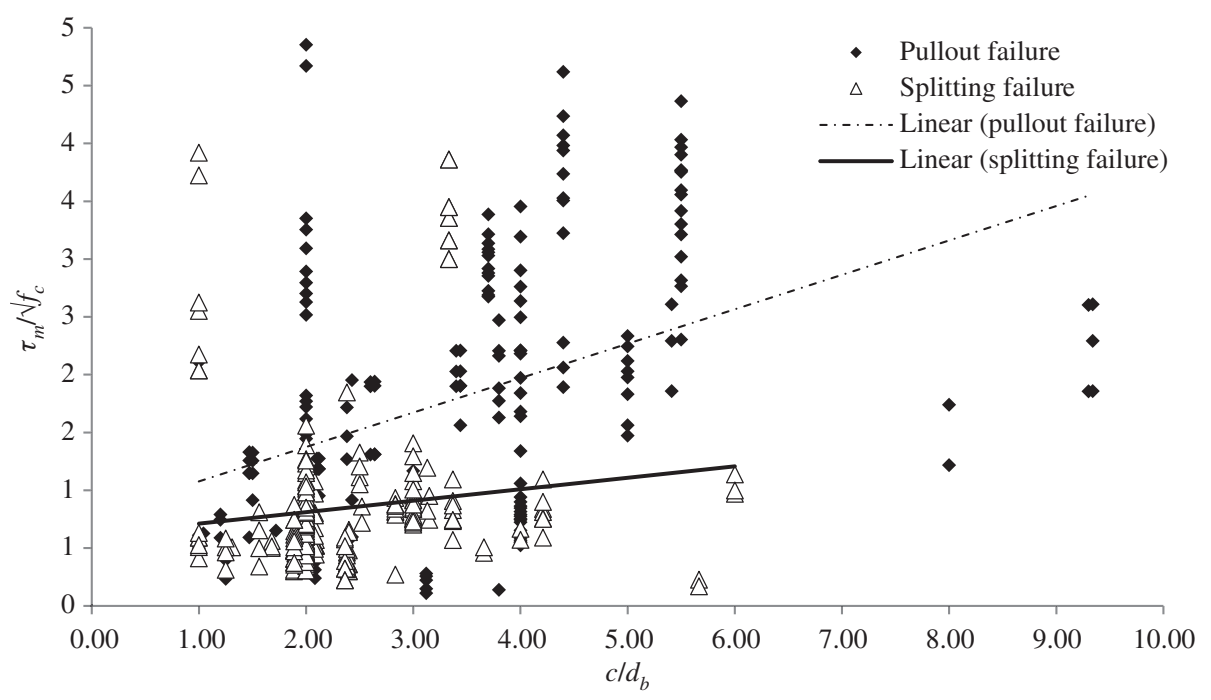

Figure 7: Normalised average bond strength with concrete cover-to-bar-diameter ratio. 


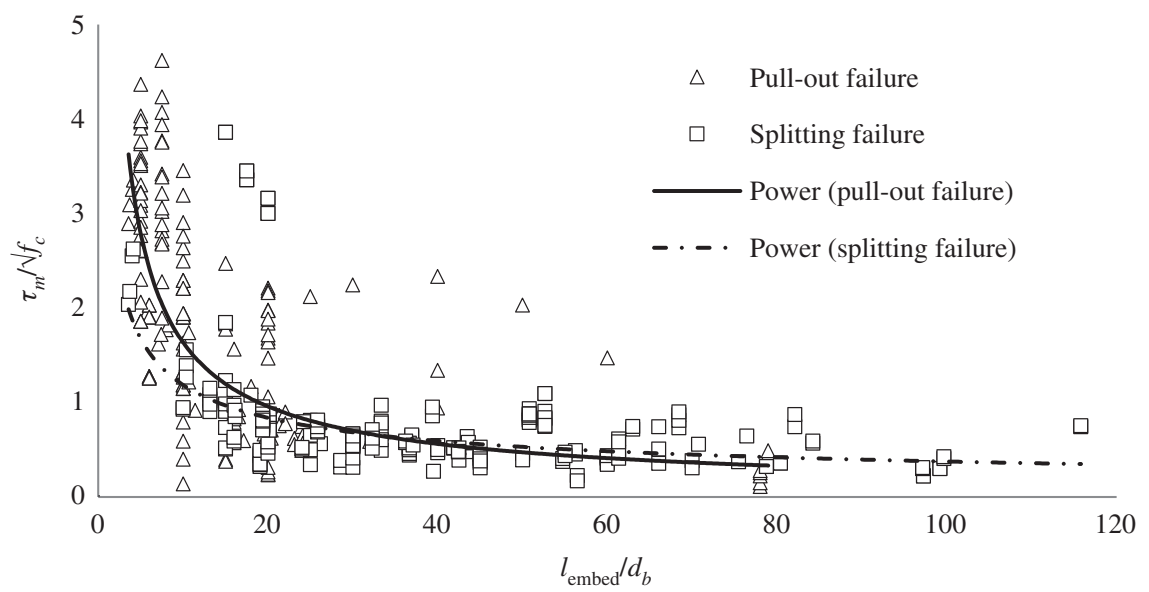

Figure 8: Variation of normalised average bond strength with normalised embedment length for pull-out and splitting failures.

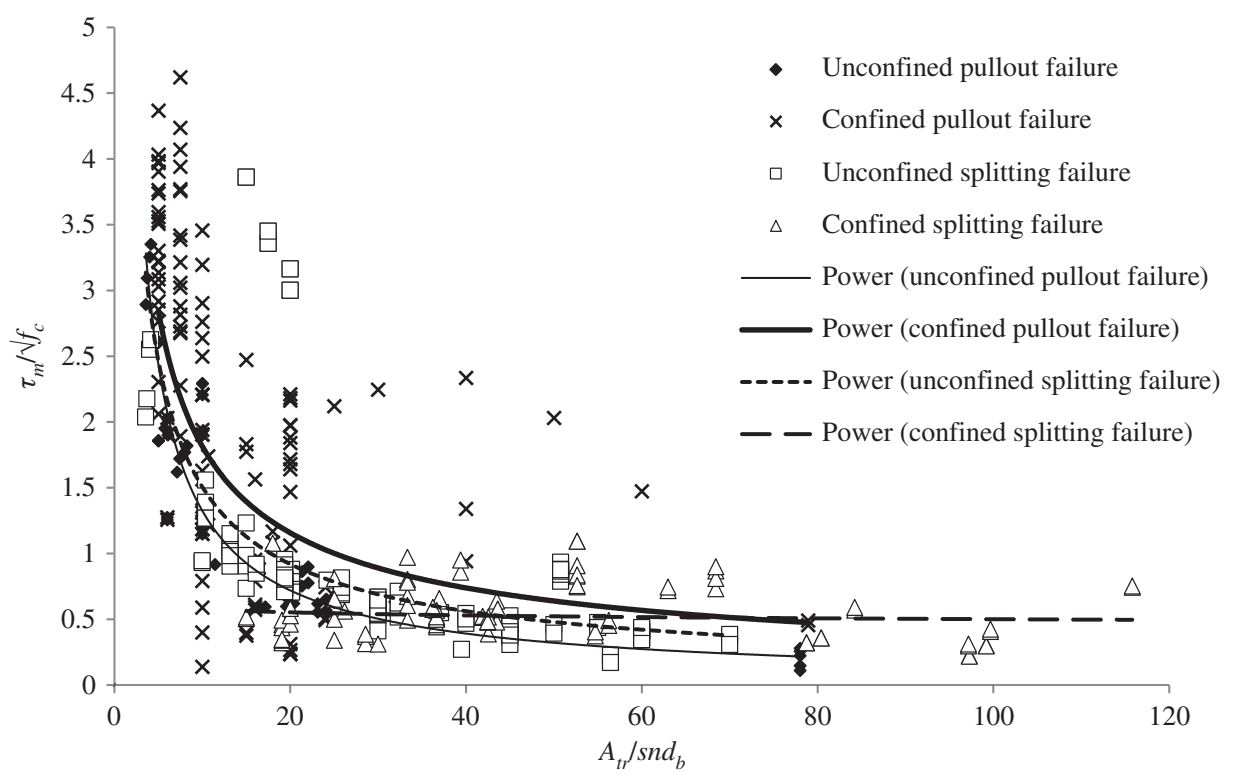

Figure 9: Normalised average bond strength against normalised transverse reinforcement effect.

for FRP rebars in concrete due to limited experimental studies.

\section{ANN}

ANN is a computational or mathematical model used for simulating the structure or functional aspects of biological neural networks. Although ANN is simple and small in size, its ability to model the human brain is astonishing [51]. The ANN that operates locally is a network of simple artificial elements (neurons). A classic multi-layer feed-forward neural network generally has three or more layers. These are the input layer, one or more hidden layers and the output layer. This study uses a typical multi-layer feed-forward neural network. Information is received from the outside environment by input layers and is passed to the neurons via an initial hidden layer. Weights are rates that describe how an input set or alternative process element in the previous layer affects this process element. Information flow between neurons is regulated by these weights. Furthermore, bias associated with the neurons in the hidden and output layers with modifiable weighted connections exists in this step. Two main processes are carried out for each neuron in the hidden and output 
layers. The effect of inputs and weights on the process elements is calculated by the first one, which is the sum of the function that computes the net input coming to a neuron [54-58].

The weighted sums of the input components are calculated by using Eq. (11), as follows:

$$
\text { net }_{j}=\sum_{i=1}^{n} w_{i j} x_{i}+\text { bias }_{j} \text {, }
$$

where net ${ }_{j}$ is the weighted sum of the $j$ th neuron for the input received from the preceding layer with $n$ neurons, $w_{i j}$ is the weight between the ith neuron and the $j$ th neuron in the preceding layer and $x_{i}$ is the output of the $i$ th neuron in the preceding layer.

The output of the $j$ th neuron Out is calculated by using Eq. 12 [57]:

$$
\text { Out }_{j}=f\left(\text { net }_{j}\right)=\frac{1}{1+e^{-\left(\text {net }_{j}\right)}} \text {. }
$$

\subsection{Back-propagation (BP) algorithm}

The BP algorithm, which is an iterated search process, calculates the error and then uses this to adjust the weights in the output layer. After that, it is distributed backwards from the output to the hidden and input nodes. The BP algorithm adjusts the weights from the output layer (Figure 10). The steepest gradient descent principle is used where the modification in weight is directed towards the negative error gradient.

Once the training is completed, the recent connection weights are kept fixed and new input models are submitted to the network in order to generate the corresponding output consistent with the internal representation of the input/output mapping.

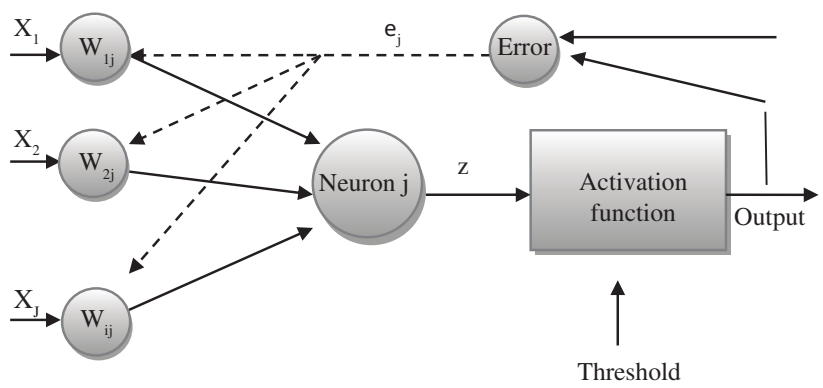

Figure 10: Neuron weight adjustments [58]. $W=$ weight between any two nodes ( $D w n$ and $D w n-1$ are the modifications in the weight at $n$ and $n-1$ iteration). $g=$ learning rate.

\subsection{Network selection}

Selecting the number of hidden layers and the neurons in each layer is an experience-based step. A few trials are necessary in order to find out the best configuration for the network [59]. The number of neurons in an ANN needs to be enough to model the problem of interest correctly. However, it must be low enough to maintain generalisation of the network. Usually, a neural network application has three phases frequently referred to as "training", "validating" and "testing". During the training step, training is given to the network, and the network is calibrated on the basis of the obtained errors. Validating is used to measure the network generalisation and to check training when generalisation stops improving and when testing has no effect on training [60].

In this study, a code is written in order to perform the computations. A BP training algorithm is utilised in a three-layer feed-forward network trained using the scaled conjugate gradient. The ANN model developed in a recent study has eight neurons (variables) in the input layer and one neuron in the output layer. A four-layer model comprising one input layer, two hidden layers and one output layer is developed. After testing multiple networks, the number of neurons in the hidden layer is matched to 30 . A 1500 iteration (epoch) is applied to the 408 database, of which 358 are used for training and 50 are used for testing. The proposed ANN model architecture is presented in Figure 11.

A comparison of the ANN model for training and testing data can be seen in Figures 12 and 13, respectively.

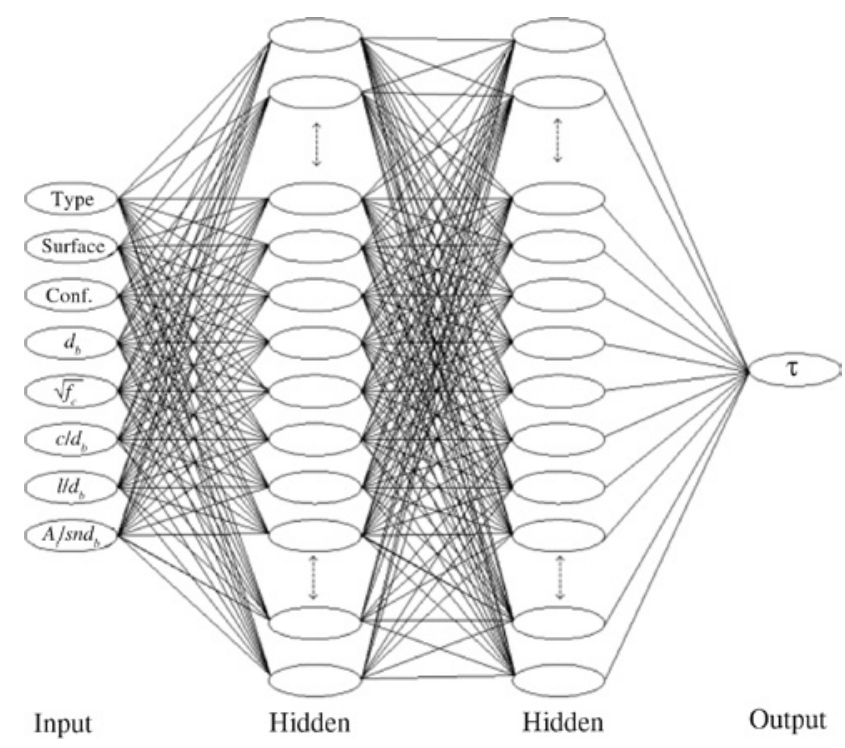

Figure 11: Architecture of the proposed ANN model. 


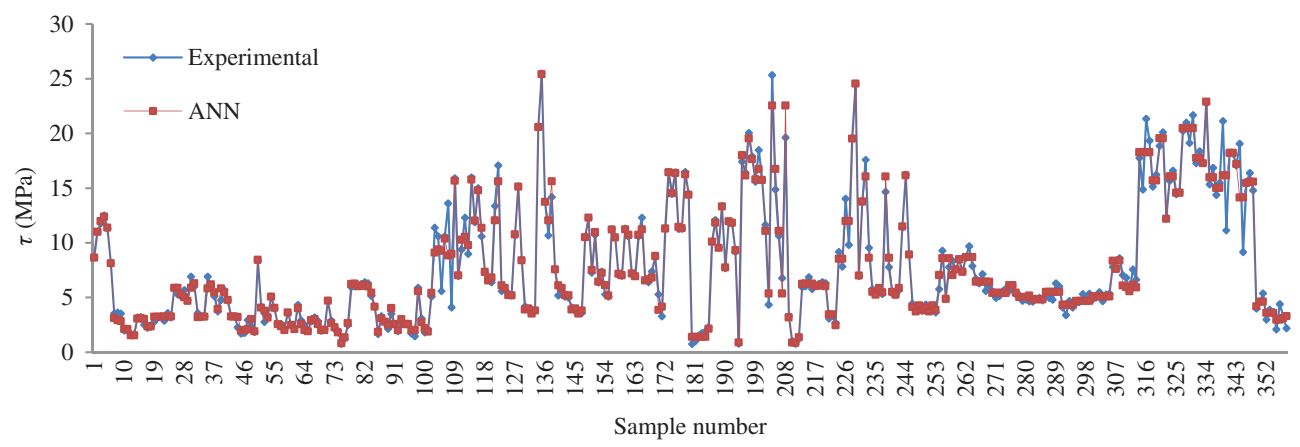

Figure 12: Comparison of the ANN model output and experimental data for training.

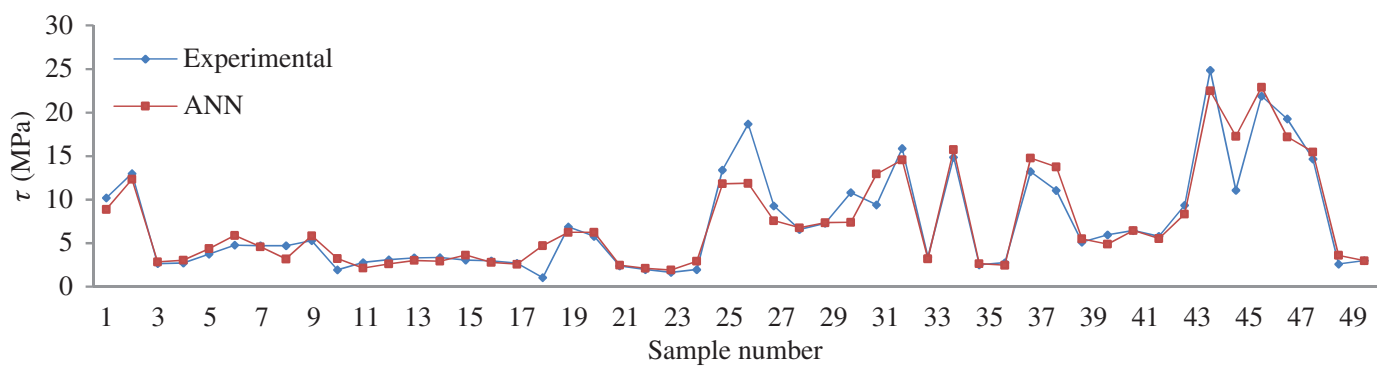

Figure 13: Comparison of the ANN model output and experimental data for testing.

The results of output data for different models' outputs are compared with experimental data. In the horizontal axis, the sample numbers are given while the vertical axis shows bonding strength in MPa. Figures 12 and 13 indicate that ANN models are accomplished in learning the correlation between the various input and output parameters.

The $R^{2}$ value of the training data demonstrates the optimised network's perfect training performance when investigating the non-linear relationship between the inputs and output. The results obtained from experimental studies and predicted using ANN is given in Figure 14. $R^{2}$ for training data is evaluated as 0.9711 and 0.8989 for testing data.

Additionally, ANN models were also developed for each beam type specimen (inverted hinge beam specimens, hinged specimens and beam splice specimens). $R^{2}$ for testing data is evaluated as $0.92,0.78$ and 0.72 for beam splice specimens, hinged specimens and inverted
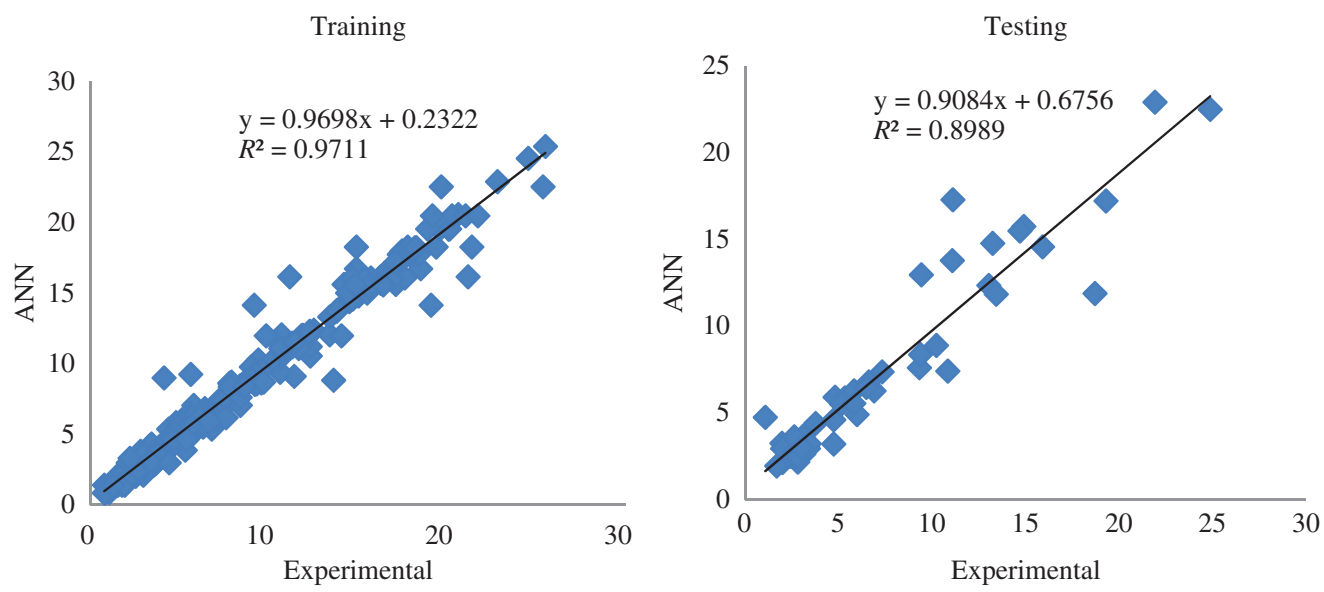

Figure 14: Scatter plot of predicted and experimental values of bond strength of proposed ANN model. 


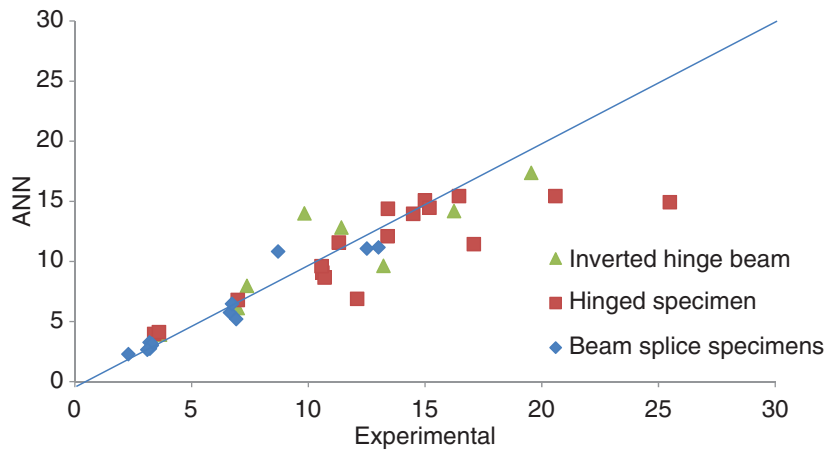

Figure 15: Comparison of ANN models for testing data of each beam type specimen (inverted hinge beam specimens, hinged specimens and beam splice specimens).

hinge beam specimens, respectively. Figure 15 shows the scatter plot of predicted and experimental values for bond strength given by the proposed ANN model for testing data of inverted hinge beam test data, hinged beam test data and beam splice specimens. Although the prediction for the grouping of all types of beam specimens and the prediction for all beam test assumptions are different, the prediction ratio is not different significantly.

\section{Bond strength equations in the literature and design codes}

Bond strength can be described as the maximum local horizontal shear force per unit area of the rebar perimeter. Bond strength equations from the literature and international design codes for FRP bars for concrete are summarised in Table 2.

\section{Statistical analysis}

Regression analysis is an effective tool used in order to build a model for material modelling operations. In this study, the $l / d$ ratio is used to estimate the bond strength $(\tau)$. However, the relationship between $\tau$ and $l / d$ was not linear and transformations in the variables were applied in order to carry out linear regression analysis. Optimum conversion is obtained when the inverse and square root $\tau$ and square root of $l / d$ is applied. Once the necessary transformations are performed, a new model is presented by applying linear regression analysis to the obtained data group. $R^{2}$ and root mean square error (RMSE) are

Table 2: Bond strength equations from the literature and international design codes.

Orangun
(1975) [61]

Breen (1977)

[62]

$\mathrm{ACl} 440.1 \mathrm{R}-$

06 [63]

CSA S806-02

[52]

$$
\begin{aligned}
& \frac{\tau}{\sqrt{f_{c}}}=\frac{d_{c s}}{1.15 k_{1} k_{2} k_{3} k_{4} k_{5} \pi d_{b}} \\
& k_{1}=\text { bar location factor: } 1.3 \text { for horizontal } \\
& \text { reinforcement placed so that }>300 \mathrm{~mm} \text { of }
\end{aligned}
$$$$
\text { fresh concrete is cast in the member below the }
$$
development length or splice; 1.0 for all other cases. $k_{2}=$ concrete density factor: 1.3 for structural low-density concrete; 1.2 for structural semi-lowdensity concrete; 1.0 for normal density concrete. $k_{3}=$ bar size factor: 0.8 for $A_{b}<300 \mathrm{~mm}^{2} ; 1.0$ for $A_{b}>300 \mathrm{~mm}^{2}$.

$k_{4}=$ bar fibre factor: 1.0 for CFRP and GFRP; 1.25 for AFRP.

$k_{5}=$ bar surface profile factor. Can be taken as $<1.0$, but not $<0.5$;

1.0 for surface-roughened or sand-coated surfaces;

1.05 for spiral pattern surfaces;

1.0 for braided surfaces;

1.05 for ribbed surfaces;

1.80 for indented surfaces.

$d_{c s}$ is the smaller of (a) the distance from the closest concrete surface to the centre of the bar being developed; or (b) two-thirds of the centre-to-centre spacing of the bars being developed. The value shall not be taken $>2.5 d_{b}$, in $\mathrm{mm}$

given to compare the results of the proposed model with the models from the literature. The normality of the variables is measured using the Shapiro-Wilk normality test, and intergroup differences were determined using the Mann-Whitney U test. Afterwards, analysis results were given with the form mean \pm standard deviation (SD) and minimum-maximum by $\mathrm{p}<0.05$.

When the data structure is analysed, a non-linear relationship between the dependent variable $(\tau)$ and 

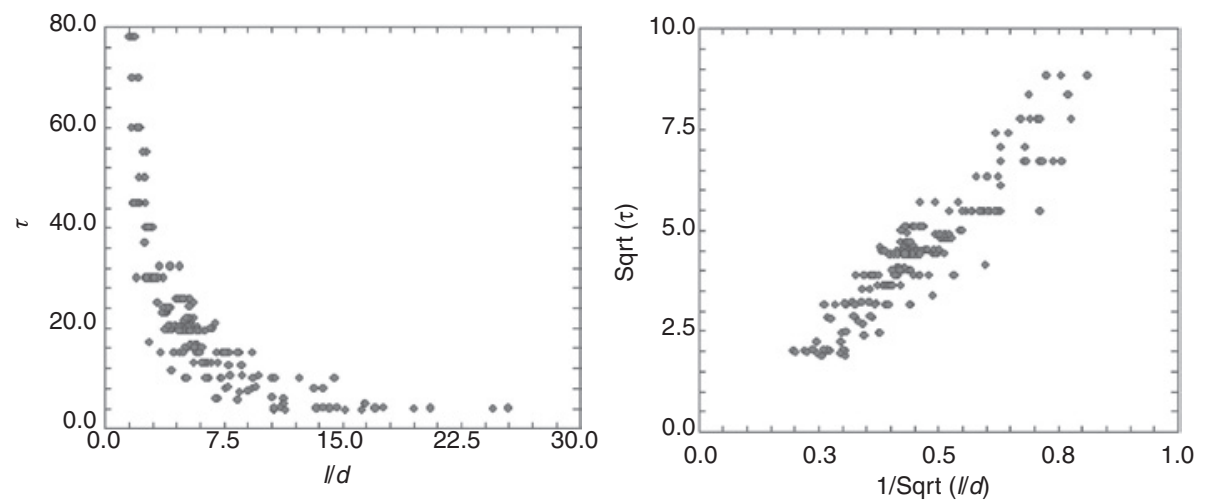

Figure 16: Subsequent conversion of the original version and scatter plots of variables.

Table 3: Regression analysis results.

\begin{tabular}{|c|c|c|c|c|c|}
\hline & $B$ (coefficient) & $95 \% \mathrm{Cl}$ for $B$ (coefficient) & Std. error for $B$ (coefficient) & $\tau$ & $A_{t r} /$ snd $_{b}$ \\
\hline Intercept & 0.1034 & $0.0825-0.1243$ & 0.0106 & 9.7397 & 0.000 \\
\hline \multirow{2}{*}{$\sqrt{\frac{l_{\text {embed }}}{d_{b}}}$} & 0.0792 & $0.0747-0.0837$ & 0.0023 & 34.840 & 0.000 \\
\hline & $R=0.9282$ & $R^{2}=0.8616$ & $F=1213.824 ; p=0.000$ & $\mathrm{MSE}=0.00242$ & \\
\hline
\end{tabular}

the independent variable $(l / d)$ is observed. As a linear regression analysis cannot be made in this case, different transformations are applied to the variables to resolve the situation. Thus, the most appropriate structure is chosen by the inverse of the square root of the dependent variable $(1 / \operatorname{sqrt}(\tau))$ and the square root of the independent variable $(l / d)$. Following the subsequent conversion of the original version, the scatter plots of the variables are given in Figure 16.

Following the conversion made in order to achieve the new model, the linear regression equation is applied and the results are given in Table 3 . The effect of confinement, as provided by transverse reinforcement, on the bond behaviour of FRP rebars $(p)$ in concrete is ignored in regression analysis. When effect transverse reinforcement is considered, multi-linear regression does not give any statically meaningful results.

The obtained regression model is

$$
\frac{1}{\sqrt{\tau}}=0.1034+0.0792 \sqrt{\frac{l_{\text {embed }}}{d_{b}}} .
$$

The established model is statistically significant $(F=1213.824, p=0.000)$ and the ratio explaining the dependent-variable arguments is $86.16 \%$. The normal probability plot of residuals of $(1 / \operatorname{sqrt}(\tau))$ is given in Figure 17.

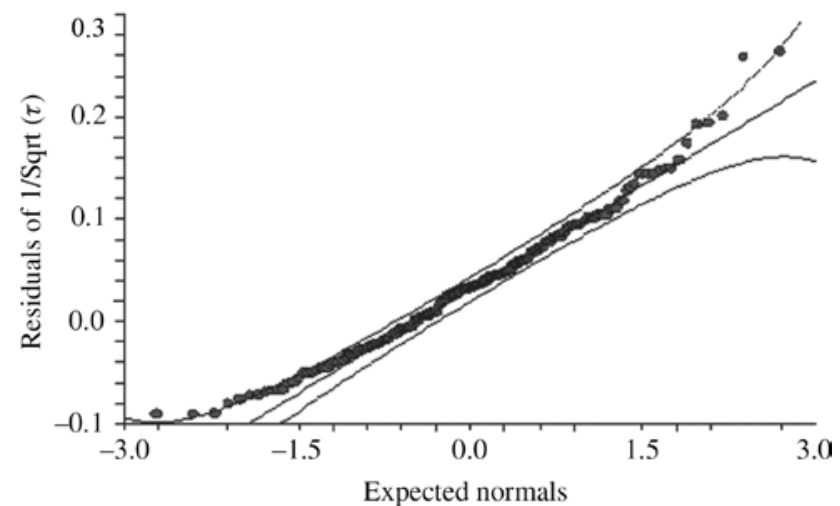

Figure 17: Normal probability plot of residuals of $(1 / \operatorname{sqrt}(\tau))$.

\section{Results and discussion}

It is seen from all the figures that the bond strength of FRP bars is affected by many parameters. Some of these parameters directly affect the FRP bond behaviour, and some have negligible effects.

\subsection{Effect of bar type and bar surface on bond strength}

The effect of the type of bar on the bond strength of FRP bars in concrete is illustrated in Figure 4, and the bar 
surface effect on the bond strength of FRP bars in concrete is illustrated in Figure 5. Specific trends have resulted in the American Concrete Institute (ACI) model becoming permanently accepted while the trend for the CSA model is insignificant. Also, Figures 4 and 5 show some negligible variations in bond strength for the effect of different bar types and surfaces, and future comparison studies need to be made using more experimental data for all different bar types and surfaces.

\subsection{Effect of concrete compressive strength $f_{c}$ on bond strength}

The change in the bond strength of FRP bars in concrete with changing concrete compressive strength is given in Figure 6. Parallel to all methods and models developed for bonding, the design of FRP bars takes into account the effect of concrete compressive strength on the bond strength of FRP bars. The bond strength of FRP bars in concrete increases as the concrete compressive strength increases.

Darwin et al. [64] observed that $\sqrt[4]{f_{c}}$ provided a better representation of concrete strength on bond strength than the more traditional $\sqrt{f_{c}}$. This illustrates that the effect of concrete compressive strength should be studied for different compressive strengths with different parameters.

\subsection{Effect of concrete-cover-to-bar-diameter ratio $(c / d)$ on bond strength}

Figure 7 shows the effect of concrete-cover-to-bar-diameter ratio on the bond strength of FRP bars in concrete. As shown in the figure, bond strength increases when $\left(c / d_{b}\right)$ ratio rises. Also, all the developed models and all the methods of bond design take into account this effect with various ratios as an effect on bonding strength. Multi-linear regression does not give any statistically meaningful results. Particularly, in the case of those specimens that failed with splitting failure, the $c / d_{b}$ ratio has no significant effect on bond strength. Additionally, all models contradict the $c / d_{b}$ effect on bond strength magnitude. This parameter needs to be studied with more experimental data.

\subsection{Effect of normalised embedment length $\left(l / d_{b}\right)$ on bond strength}

Figure 8 illustrates the effect of normalised embedment length on the bond strength of FRP bars in concrete.

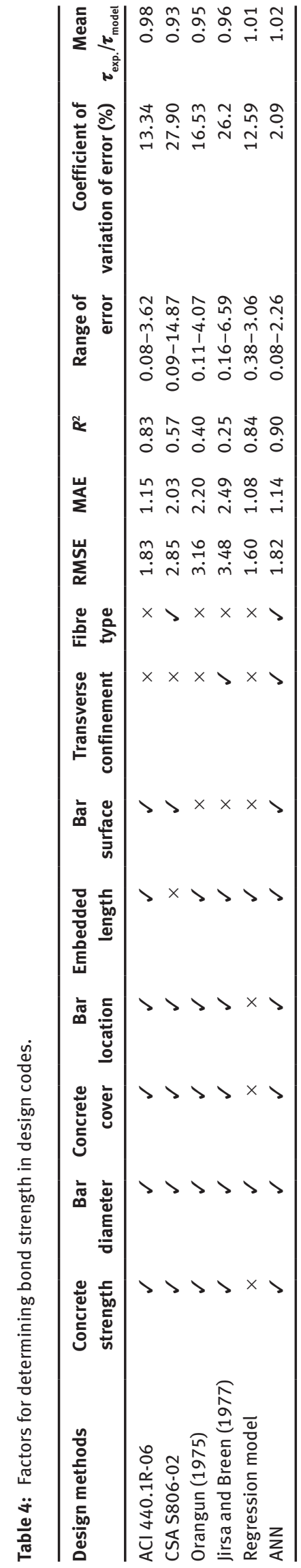


It is observed from the experimental studies that as the $\left(l / d_{b}\right)$ ratio rises, the FRP bars' bond strength in concrete decreases. Unlike with the CSA code, the proposed model uses the effect of normalised embedment length with the power of one-half like the trend of the ACI code.

\subsection{Effect of confinement $\left(A_{t r} / s n d_{b}\right)$ on bond strength}

The presence of transverse reinforcement confining the concrete improves the bond strength of the FRP bars in concrete. Nevertheless, the few experimental studies
A

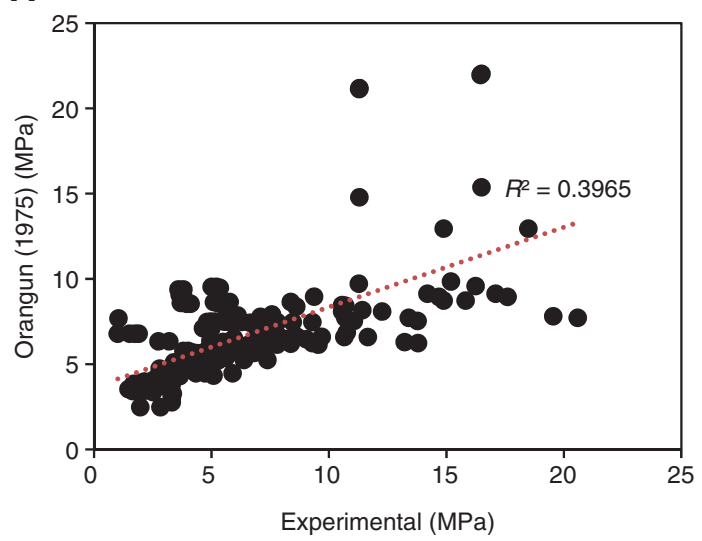

C

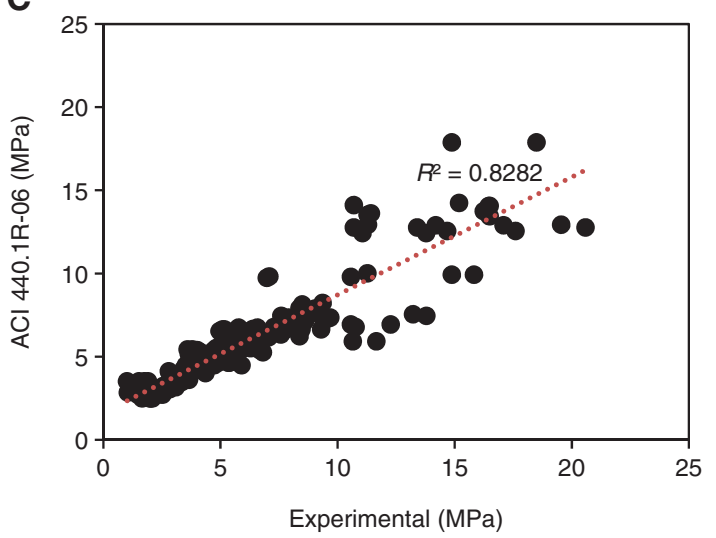

E

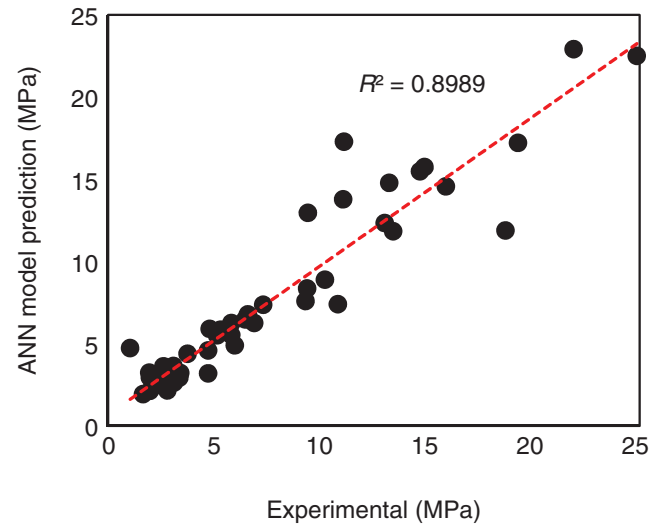

B

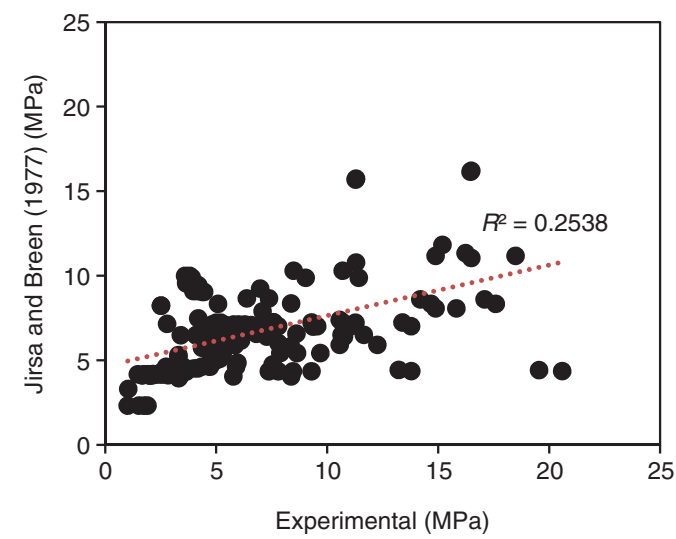

D

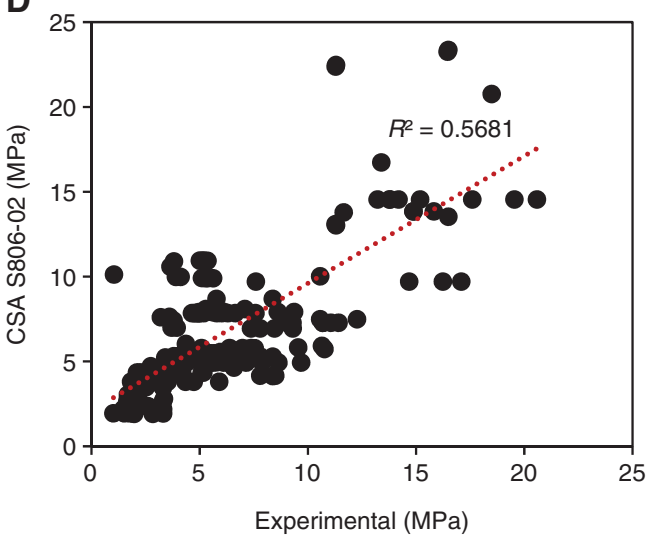

$\mathbf{F}$

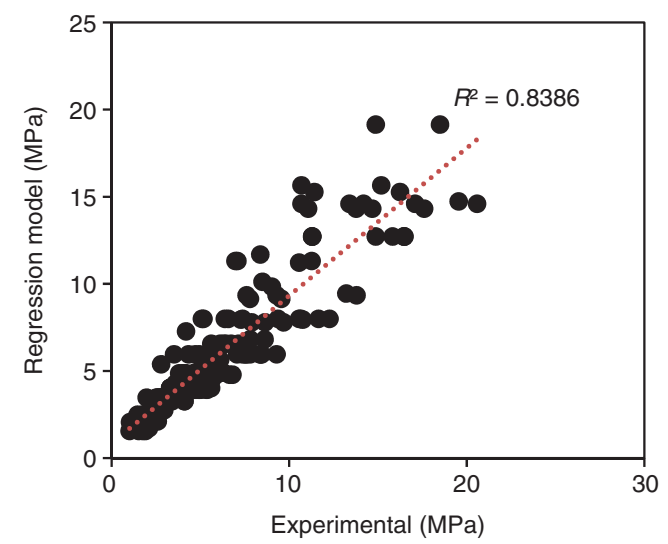

Figure 18: Comparison of experimental FRP bond strength and prediction method of (A) Orangun (1975), (B) Jirsa and Breen (1977), (C) ACI 440.1R-06, (D) CSA S806-02, (E) ANN and (F) regression analysis. 
that have been carried out into the effect of transverse reinforcements on the bond behaviour of FRP rebars in concrete do not validate this theory definitively, as shown in Figure 9. In particular, the specimens with splitting failure have negligible confinement effect on the bond behaviour of FRP rebars in concrete. However, extra studies are needed in order to verify this using more developed beam test data.

\subsection{Comparison of experimental data within ANN, regression analysis, formulas and codes}

In this study, RMSE criteria and mean absolute error (MAE) are employed to evaluate the performance of the models. The definitions of the criteria are as follows:

$$
\begin{aligned}
\text { RMSE } & =\sqrt{\frac{1}{N} \sum_{s=1}^{N}\left(S_{s}-\tau_{s}\right)^{2},} \\
\text { MAE } & =\frac{1}{N} \sum_{i=1}^{N}\left|S_{s}-\tau_{s}\right|,
\end{aligned}
$$

where $\tau_{s}$ is the bond strength of FRP bars in concrete, $S_{s}$ is the predicted value and $N$ is the total number of data points in each set of data.

The statistical values of RMSE in ANN, the regression model, the Jirsa and Breen (1977) formula, the Orangun (1975) formula, and the ACI and the CSA equations are found to be 1.82, 1.60, 3.48, 3.16, 2.85 and $1.83 \mathrm{MPa}$, respectively. Similarly, the values for MAE, $R^{2}$, range of error, coefficient of variation of error and the mean of the experimental model results are given in Table 4.

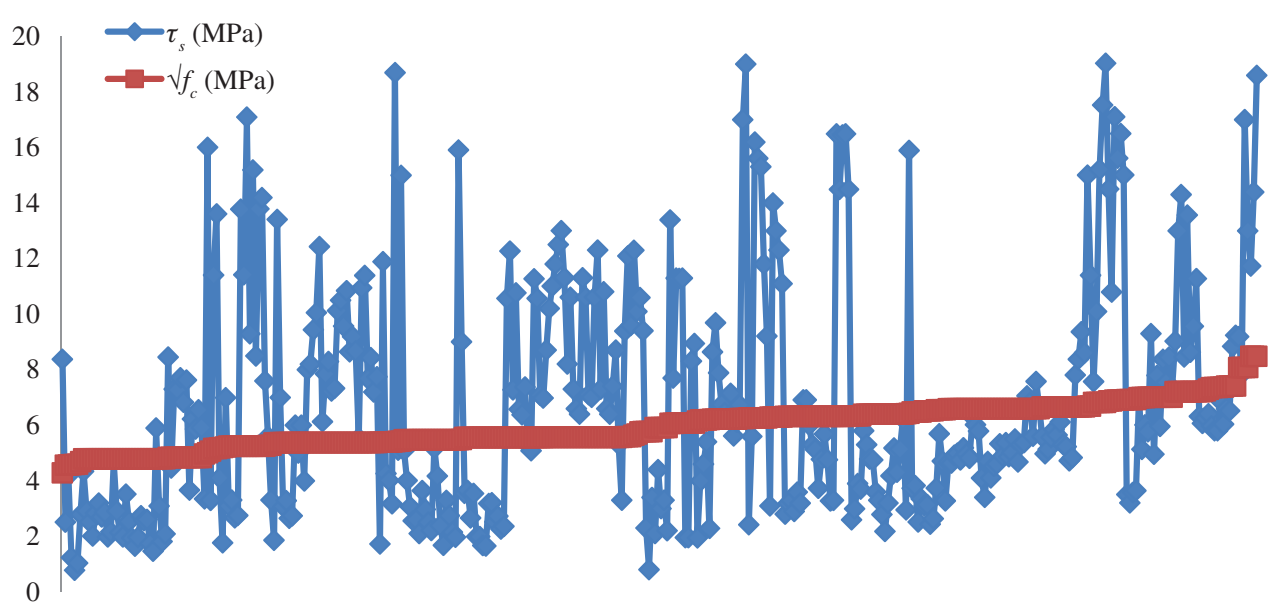

Figure 19: Change in the bond strength of FRP bars in concrete with changing square root of concrete compressive strength.

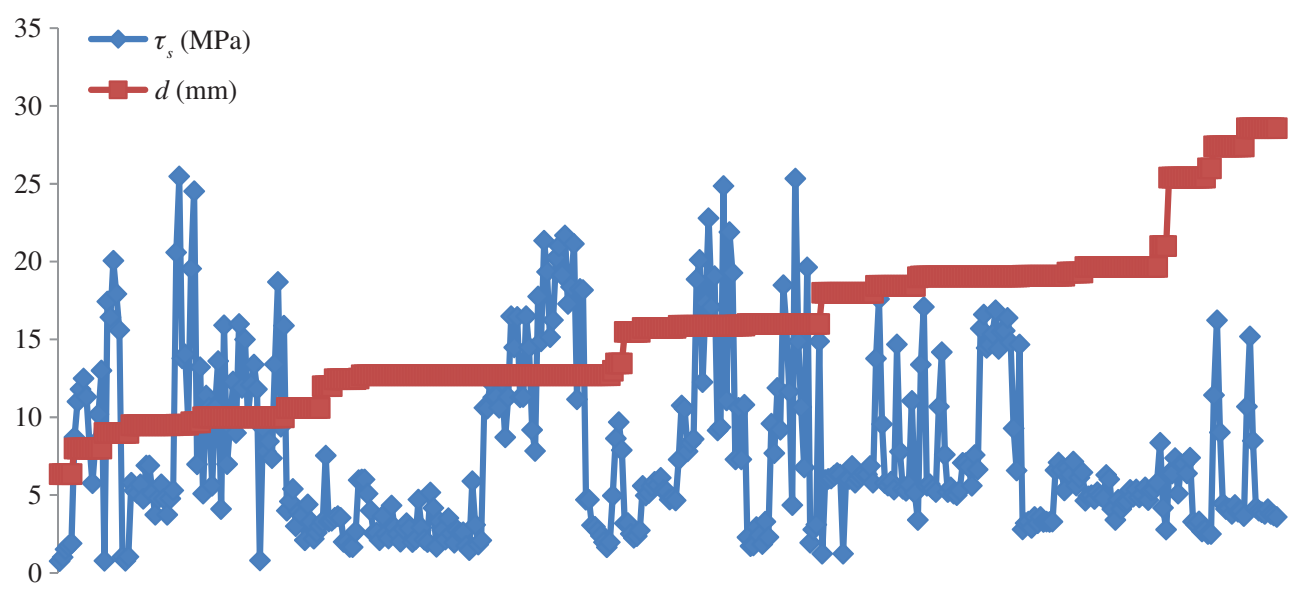

Figure 20: Change in the bond strength of FRP bars in concrete with changing diameter of rebar. 


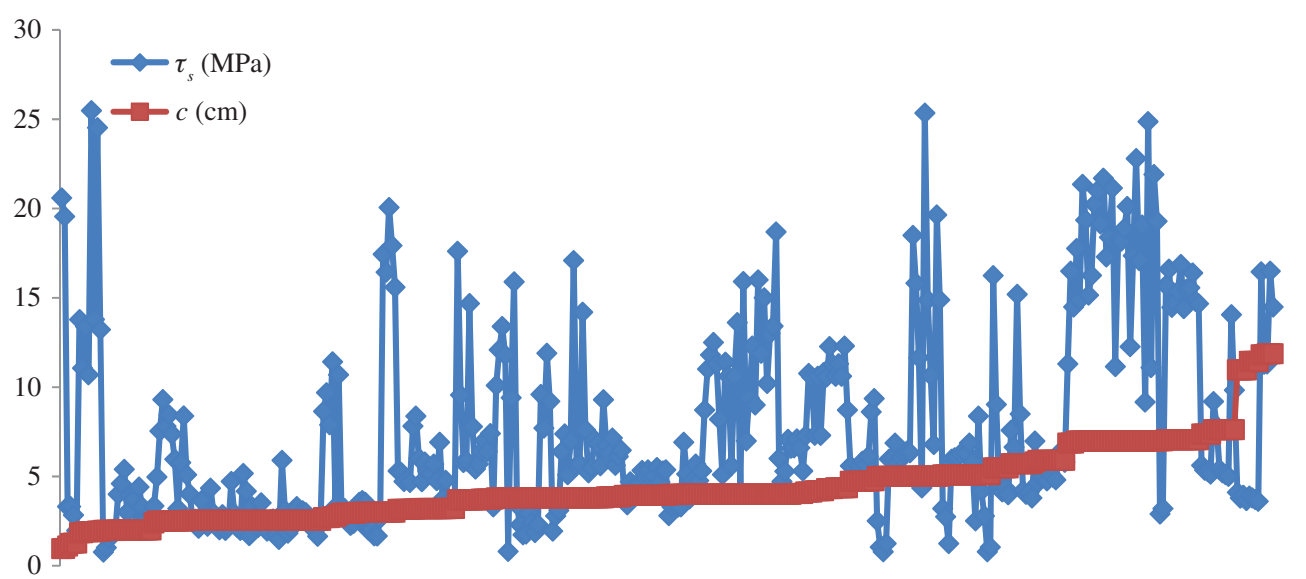

Figure 21: Change in the bond strength of FRP bars in concrete with changing concrete cover.

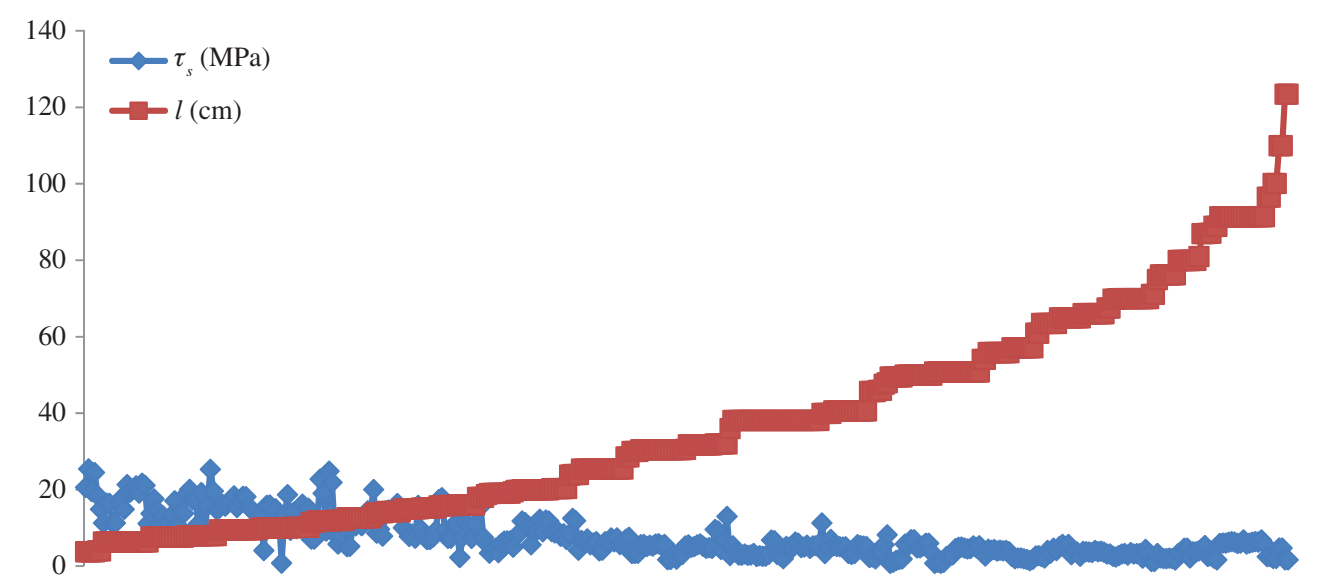

Figure 22: Change in the bond strength of FRP bars in concrete with changing embedment length.

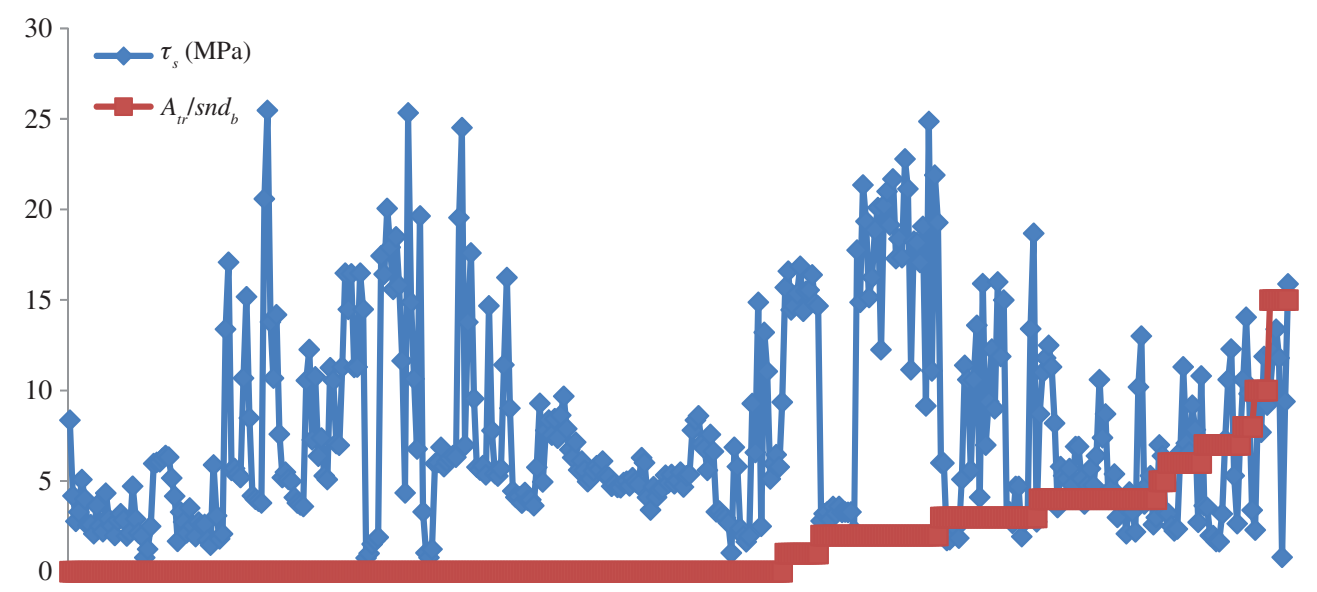

Figure 23: Change in the bond strength of FRP bars in concrete with changing transverse reinforcement ratio.

The bond strength of FRP bars to concrete calculated using different design specifications is illustrated in Table 4. Concrete strength, bar diameter, concrete cover and bar location are taken into account for all methods except the regression model, which considers only concrete strength, bar diameter, embedment length and bar 


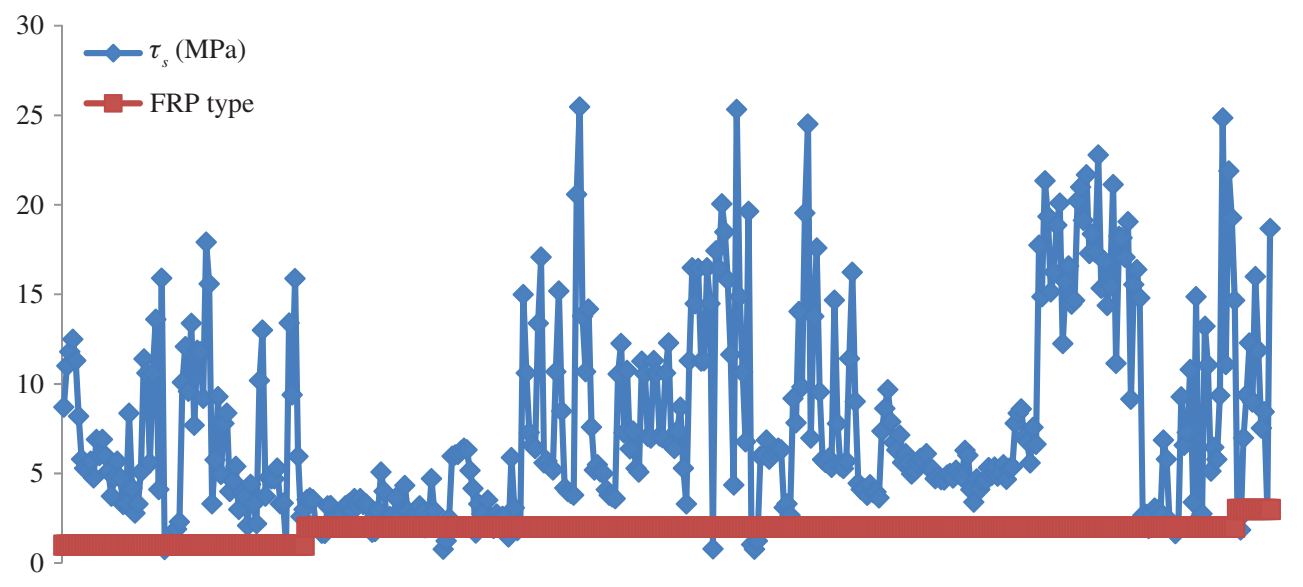

Figure 24: Change in the bond strength of FRP bars in concrete with changing FRP type.

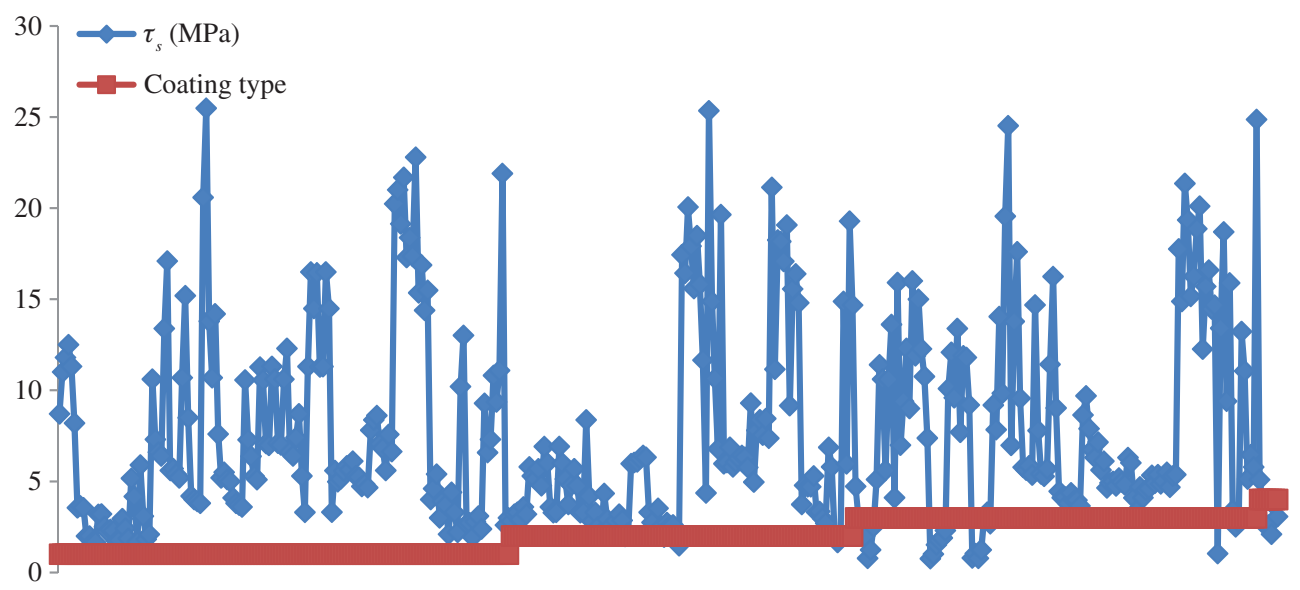

Figure 25: Change in the bond strength of FRP bars in concrete with changing FRP coating type.

location. Only the CSA S806-02 code fails to take embedment length into account for bond strength prediction. The effects of all the parameters considered or not considered that influence bond strength have not yet been clarified. Therefore, further investigation is needed.

The bond strength equations for FRP bars to concrete that exist in different design methods [A - Orangun (1975), B - Jirsa and Breen (1977), C - ACI 440.1R-06, D - CSA S806-02, E - ANN, F - regression analysis] are used and compared with the experimental results. Figure 18 shows the comparison of experimental FRP bond strengths and the strengths calculated by prediction methods.

In order to estimate bond strength, many parameters need to be considered, such as type of fibre, type of rebar surface, bar cast position, transverse reinforcement, bar diameter, compressive strength of concrete, concrete cover and embedment length. The peak bond strength of FRP rebars in concrete is significantly affected by the compressive strength of concrete, concrete cover, embedment length and bar diameter. Both ACI 440 and the proposed ANN model take into account these parameters, which is why their results are similar when estimating the bond strength of FRP rebars in concrete. However, the ANN model gives better results than the ACI 440 and other design methods.

In order to investigate what parameters are most important, a single bar graph showing [(change in bond strength)/(change in parameter value)] for the seven parameters used in the model are given in Figures 19-25. It is clearly seen from these figures that embedment length is very essential on the bond strength of FRP bars in concrete. Additionally, the effect of concrete compressive strength, diameter of rebar and concrete cover is remarkable. However, the transverse reinforcement ratio, FRP type and FRP coating type have no expressive effect on predicting the bond strength of FRP bars in concrete when all data are observed without any separation. 


\section{Conclusion}

The ANN model and the regression analysis model developed in this study are used to predict the bond strength of FRP bars in concrete. In order to do this, a database consisting of 408 different experimental bond beam tests was compiled, of which 358 records were used for training and 50 were used for testing (chosen randomly). The following conclusions were obtained from this study:

- It is suggested that the proposed ANN model can simply and accurately predict the bond strength of FRP bars in concrete.

- Given the complex relationship between the bond strength of FRP bars in concrete and the parameters affecting bond strength, the proposed ANN model is a potential alternative approach to traditional statistical methods.

- The proposed ANN model has also been used to perform parametric studies, and it correctly predicts the influence of the various input parameters relevant with the literature.

- The proposed model can be used to predict the bond strength of FRP bars in concrete, avoiding costly and difficult experimental tests that require detailed and specific training, equipment and expertise.

- The recommended simple regression analysis model is able to estimate the bond strength of FRP bars in concrete with ease and gives better result than the ACI and CSA models.

- The bar surface and bar type has no significant effect on the bond strength of FRP bars in concrete. Therefore, it is recommended that more tests are carried out in order to form a definitive conclusion about the effect of bar surface and bar type on the bond strength of FRP bar in concrete.

- Structural engineers may use this simple equation to predict the bond strength of FRP bars in concrete before testing concrete strength, thus avoiding uneconomic tests that require specialist training and instruments.

For confined beam specimens, more experimental studies are needed in order to quantify the effect of concrete confinement as provided by transverse reinforcement.

\section{References}

[1] Kara IF, Ashour AF, Köroğlu MA. Compos. Struct. 2015, 129, 111-121.
[2] Lee J-Y, Kim T-Y, Kim T-J, Yi C-K, Park J-S, You Y-C, Park Y-H. Compos. Pt B Eng. 2008, 39, 258-270.

[3] Hao Q, Wang Y, He Z, Ou J. Construct. Build. Mater. 2009, 23, 865-871.

[4] Bond A. Development of Straight Reinforcing Bars in Tension, ACl 408R-03, 2003.

[5] Tighiouart B, Benmokrane B, Gao D. Construct. Build. Mater. 1998, 12, 453-462.

[6] Köroğlu MA, Ceylan M, Arslan MH, İlki A. Eng. Struct. 2012, 42, 23-32.

[7] Köroglu M, Köken A, Arslan M, Çevik A. Sci. Iran. Trans. A Civil Eng. 2013, 20, 1101.

[8] Cevik A, Arslan MH, Köroğlu MA. KSCE J. Civil Eng. 2010, 14, 371-384.

[9] Yarar A, Onucyıldız M, Copty NK. J. Hydrol. 2009, 365, 329-334.

[10] Yarar A. Water Resour. Manage. 2014, 28, 553-565.

[11] Yuksel SB, Yarar A. Metaheur. Eng. 2014, 83-89.

[12] Dahou Z, Sbartaï ZM, Castel A, Ghomari F. Eng. Struct. 2009, 31, 1724-1733.

[13] Golafshani EM, Rahai A, Sebt MH, Akbarpour H. Construct. Build. Mater. 2012, 36, 411-418.

[14] Golafshani E, Rahai A, Sebt M. Mater. Struct. 2015, 48, 1581-1602.

[15] International Union of Testing and Research Laboratories for Materials and Structures, RILEM Technical Recommendations for the Testing and Use of Construction Materials, Spon, 1994.

[16] Tighiouart B, Benmokrane B, Mukhopadhyaya P. Construct. Build. Mater. 1999, 13, 383-392.

[17] Shihata A. CFRP Strengthening of RC Beams with Corroded Lap Spliced Steel Bars, University of Waterloo: Waterloo, Canada, 2011.

[18] Yan F, Lin Z. Compos. Pt B Eng. 2016, 92, 420-433.

[19] Benmokrane B, Tighiouart B. Mater. J. 1996, 93, 254-259.

[20] Wambeke BW, Shield CK. ACI Struct. J. 2006, 103, 11.

[21] Mosley CP, Tureyen AK, Frosch RJ. ACI Struct. J. 2008, 105, 634

[22] Baena M, Torres L, Turon A, Barris C. Compos. Pt B Eng. 2009, 40, 784-797.

[23] Xue W, Zheng Q, Yang Y, Fang Z. J. Reinf. Plast. Compos. 2014, 33, 895-910.

[24] Harajli M, Abouniaj M. J. Compos. Constr. 2010, 14, 659-668.

[25] Malvar L, Cox J, Cochran KB. J. Compos. Constr. 2003, 7, 154-163.

[26] Daniali S. ASCE 1990, 2, 1182-1191.

[27] Faza SS, GangaRao HVS. Transport. Res. Rec. 1990, 1290, 185-193.

[28] Ehsani MR, Saadatmanesh H, Tao S. J. Struct. Eng. 1996, 122, 247-254.

[29] Kanakubo T, Yonemaru K, Fukuyama H, Fujisawa M, Sonobe Y. ACl Spec. Publ. 1993, 138, 767-767.

[30] Makitani E, Irisawa I, Nishiura N. Spec. Publ. 1993, 138, 315-332.

[31] Retika AC, Shield C, French C. Thermal and Mechanical Fatigue Effects on GFRP Rebar-Concrete Bond, 1997.

[32] Shield C, French C, Hanus J. Spec. Publ. 1999, 188, 393-406.

[33] Tepfers R, Hedlund G, Rosinski B. Second International Conference on Composites in Infrastructure, Tucson, Arizona, USA, 1998.

[34] Cosenza E, Manfredi G, Realfonzo R. J. Compos. Constr. 1997, 1, 40-51.

[35] Cosenza E, Manfredi G, Pecce M, Realfonzo R. Spec. Publ. 1999, 188, 347-358. 
[36] Pecce M, Manfredi G, Realfonzo R, Cosenza E. J. Mater. Civil Eng. 2001, 13, 282-290.

[37] DeFreese JM, Roberts-Wollmann CL. Glass Fiber Reinforced Polymer Bars as Top Mat Reinforcement for Bridge Decks, Virginia Center for Transportation Innovation and Research: Virginia, USA, 2002.

[38] Maji A, Orozco A. Exp. Mech. 2005, 45, 35-41.

[39] Aly R, Benmokrane B, Ebead U. J. Compos. Constr. 2006, 10, 287-294.

[40] Aly R, Benmokrane B, Ebead U. ACI Struct. J. 2006, 103, 857.

[41] Taşliged A. Lap Splice Behavior and Strength of CFRP Rolls, Middle East Technical University: Ankara, Turkey, 2008.

[42] Aly R. Can. J. Civil Eng. 2007, 34, 1149-1158.

[43] Okelo R. J. Aerosp. Eng. 2007, 20, 133-140.

[44] Rafi MM, Nadjai A, Ali F. J. Compos. Mater. 2007, 41, 2657-2673.

[45] Thamrin R, Kaku T. J. Compos. Constr. 2007, 11, 129-137.

[46] Choi D-U, Chun S-C, Ha S-S. J. Kor. Concr. Inst. 2009, 21, 65-74.

[47] Sandstrom RJ. Bond Behavior of Fiber Reinforced Polymer Bars Under Hinged Beam Conditions, 2011.

[48] Choi D-U, Chun S-C, Ha S-S. Eng. Struct. 2012, 34, 303-313.

[49] Garcia R, Helal Y, Pilakoutas K, Guadagnini M. Construct. Build. Mater. 2014, 50, 340-351.

[50] Duan Z-H, Kou S-C, Poon CS. Construct. Build. Mater. 2013, 40, 1200-1206.

[51] Anderson JA. IEEE Trans. Syst. Man Cybernet. 1983, 5, 799-815.

[52] Canadian Standards Association, CSA-S806-02, Design and Construction of Building Components with Fibre-Reinforced
Polymers, Canadian Standards Association, Mississauga, Ontario, Canada, 2002.

[53] Quayyum S. Bond Behaviour of Fibre Reinforced Polymer (FRP) Rebars in Concrete, University of British Columbia: Okanagan, Canada, 2010.

[54] Günaydın HM, Doğan SZ. Int. J. Proj. Manage. 2004, 22, 595-602.

[55] Arbib MA. The Handbook of Brain Theory and Neural Networks. MIT Press: London, England, 2003.

[56] Sarıdemir M, Topçu IBB, Özcan F, Severcan MH. Construct. Build. Mater. 2009, 23, 1279-1286.

[57] Caglar N. Construct. Build. Mater. 2009, 23, 3225-3232.

[58] Alshihri MM, Azmy AM, El-Bisy MS. Construct. Build. Mater. 2009, 23, 2214-2219.

[59] Cachim PB. Construct. Build. Mater. 2011, 25, 4175-4180.

[60] Atici U. Expert Syst. Appl. 2011, 38, 9609-9618.

[61] Orangun C, Jirsa JO, Breen JE. The Strength of Anchored Bars: A Reevaluation of Test Data on Development Length and Splices. Center for Highway Research, University of Texas at Austin: Austin, USA, 1975.

[62] Orangun C, Jirsa J, Breen J. J. Proc. 1977, 74, 114-122.

[63] A.C. 440, Guide for the Design and Construction of Structural Concrete Reinforced with FRP Bars, American Concrete Institute: Farmington Hills, MI, USA, 2007.

[64] Darwin D, Zuo J, Tholen ML, Idun EK. Development Length Criteria for Conventional and High Relative Rib Area Reinforcing Bars, University of Kansas Center for Research Inc.: Lawrence, Kansas, USA, 1995. 